\title{
RECORD CENTER ARSIP SURAT KEPUTUSAN (SK) UNTUK UNIVERSITAS
}

\author{
Ni Wayan Wisswani, I Gusti Ngurah Bagus Catur Bawa, I Wayan Candra Winetra \\ Jurusan Teknik Elektro, Politeknik Negeri Bali, Kampus Bukit Jimbaran, Kuta Selatan, Badung, \\ Kode Pos 80364 Tuban \\ E-mail :wisswani@pnb.ac.id
}

\begin{abstract}
Abstrak
Pengelolaan arsip bagi organisasi adalah sebuah kebutuhan. ANRI merekomendasikan pengelolaan arsip bukti otentik secara digital. Universitas sebagai salah satu organisasi juga memerlukan digitalisasi manajemen pengelolaan arsip. Khususnya arsip dokumen pengelolaan surat keputusan (SK) merupakan dokumen penting yang menyangkut riwayat kegiatan universitas. Digitalisasi pengelolaan arsip membantu mengatasi kelemahan pengelolaan arsip manual yang rentan rusak dan hilang serta biaya pengelolaan yang besar. Upaya digitalisasi dilakukan dengan mengembangkan aplikasi manajemen arsip berbasis komputer menggunakan PHP dan MYSQL. Aplikasi ini mengelola transaksi pengarsipan berkas SK universitas secara terpusat agar dapat menyimpan histori kegiatan untuk pengambilan keputusan dan sebagai media penyimpanan bersama.
\end{abstract}

Kata Kunci: Arsip, Arsip elektronik, distribusi file, aplikasi Web.

\begin{abstract}
Archive management for organizations is a necessity. ANRI recommends digital records archive management of evidence. University as one of the organizations also requires digitalization of archive management. In particular, management archives of decision letter documents (SK) are important documents that relate to the history of university activities. Digitalization of archive management helps address the weaknesses of managing damaged, lost and vulnerable manual archives and large management costs. Digitalization efforts are done by developing a computer based archive management application using PHP and MYSQL. This application manages university file archiving transactions centrally in order to keep activity history for decision making and as a shared storage media.
\end{abstract}

Keywords: Archive, Electronic archives, file distribution, Web applications.

\section{PENDAHULUAN}

Arsip merupakan dokumentasi resmi catatan berbagai rekaman kegiatan atau peristiwa yang telah dilakukan oleh sebuah organisasi (Wisswani, 2018). Arsip merupakan sumber informasi bagi organisasi itu sendiri dan para stakeholdernya, karena merupakan bahan bukti yang dapat di pertanggungjawabkan kebenarannya atas seluruh aktivitas yang terjadi dalam organisasi (Rifauddin, 2016). Arsip dapat berupa naskah perjanjian/kontrak, akta pendirian perusahaan, dan surat keputusan yang kebanyakan dikelola secara manual dan membutuhkan resource yang besar agar tetap memberi nilai guna (Mulyono, 2011). Badan Arsip Nasional Republik Indonesia (Arsip Nasional Republik Indonesia ,2012 ) menyatakan pengelolaaan arsip berbasis teknologi dapat digunakan sebagai bukti otentik digital. Arsip digital lebih sesuai dengan kebutuhan zaman yang menuntut kecepatan berbagi, kemudahan akses dan fleksibilitas dalam berjejaring (Triono,2015), serta meningkatnya performa organisasi (Widiatmoko,2017).

Menurut (Machsun dan ANRI) arsip digital merupakan alih media bentuk arsip fisik menjadi file digital sehingga arsip dapat dikelola secara elektronik serta didistribusikan melalui jaringan komputer dengan teknologi sistem informasi. (Sun min) telah membuat sistem arsip untuk mengelola data arsip terkait geologi sebuah kabupaten dan propinsi. (Dessy) juga membuat sistem pengarsipan yang mengelola absensi dosen baik dalam keseharian mupun dalam proses perkuliahan, pengelolaan surat masuk dan keluar pada Fakultas Teknik Universitas Negeri Yogyakarta.

Aspek pendistribusian file kepada semua pihak pemakai adalah aspek penting dalam 
pengembangan sistem arsip digital. Berbagai metode sharing file dalam mengelola arsip juga telah dilakukan diantaranya, (Jian) melakukan penelitian untuk sharing file arsip bersama dengan metode cloud computing yang memungkinkan pelacakan file bersama yang tidak diketahui pemiliknya. (Thomas) memperkenalkan teknik Percival yang mengelola arsip dalam jangka panjang dengan penyimpanan terdistribusi. (Neal) menghasilkan software pengarsip file digital koleksi otoritas publik untuk mengidentifikasi, mengekstrak dan menyiapkan arsip digital untuk dimasukkan ke dalam media penyimpanan. (Gudakesa, dkk) melakukan sharing file dengan model host to host yang memungkinkan proses sinkronisasi data antara pihak yang berelasi. (chandraprabath) membuat teknik untuk mekanisme berbagi data yang aman yang disebut LockBox yang melakukan pengolahan data menggunakan data hiding dan key sharing diantara pengguna yang disediakan oleh sistem secara otomatis.

Teknologi lain selain file sharing adalah pengembangan layanan arsip online dengan akses melalui teknologi web. Penelitian pengembangan sistem dengan teknologi web juga masih dilakukan diantaranya, (Cenk) menggunakan teknologi web untuk komunikasi antara pelayanan medis untuk memberitahukan layanan darurat kepada dokter. (Angry) menggunakan web untuk aplikasi cepat mengkonfirmasi penculikan, (Ratna) mengunakan teknologi web untuk memberikan informasi bahan alat upacara dalam agama hindu.

Pada penelitian ini dikembangkan digitalisasi manajemen arsip untuk surat keputusan pada universitas berteknologi web yang mengedepankan efisiensi entry data, penditribusian file secara otomatis. Pengembangan sistem dilakukan dengan menggunakan metodologi waterfall dan diimplementasikan dengan bahasa pemrograman PHP dan MySQL. Sistem ini akan berfungsi sebagai media penyimpan dan sharing file arsip digital terkait surat keputusan bagi seluruh civitas akademik universitas.

\section{METODE PENELITIAN}

Penelitian ini dikembangkan dengan metode waterfall (sommerville, 2011) yaitu sebuah metode pengembangan sistem yang klasik. Dengan tahapan seperti gambar 1 berikut ini:

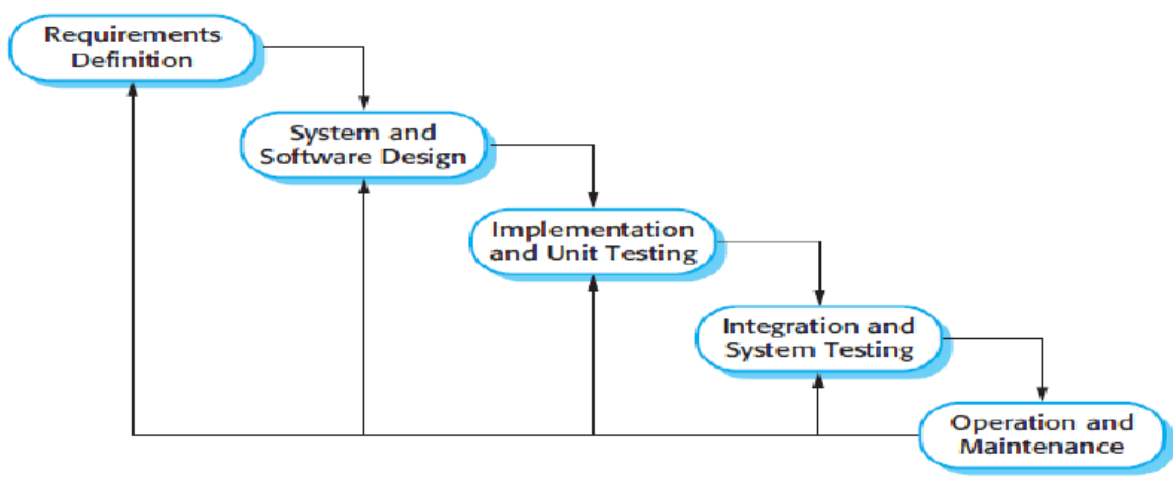

Gambar 1. Metode Waterfall

Sumber: Sommerville, 2011

a. Requirements analysis and definition Tahapan ini dilakukan untuk menentukan kebutuhan dan fungsi dari sistem arsip digital yang dibuat.

b. System and software design

Dari proses ini akan dihasilkan gambaran sistem serta kebutuhan baik perangkat keras maupun perangkat lunak

c. Implementation and unit testing

Hasil design sistem yang diperoleh pada tahapan sebelumnya diwujudkan dalam program aplikasi yang terdiri dari modul modul sistem. Modul tersebut kemudian diuji untuk memastikan bahwa subsistem memenuhi spesifikasi kebutuhan yang telah didefinisikan.

d. Integration and system testing
Tahapan ini memastikan keseluruhan sub modul yang telah terintegrasi merupakan sistem yang sesuai dengan kebutuhan perangkat lunak yang dibutuhkan end user dalam pengelolaan arsip surat keputusan universitas.

\section{HASIL DAN PEMBAHASAN}

\section{1 Requirement Analisis}

Untuk mengetahui bisnis proses eksisting pengarsipan file surat keputusan pada universitas, dilakukan penelitian pada sebuah universitas di Bali. Proses pengajuan dan pengarsipan dokumen ini dilakukan secara personal oleh pegawai atau dosen sebagai koordinator kegiatan. Prosesnya dimulai dengan membuat draft SK dan kemudian 
meminta nomer surat pada unit Humas. SK yang sudah memiliki nomer selanjutnya ditandatangani direktur sebagai pejabat utama. SK yang telah ditandatangani dibagikan kepada staff yang terlibat dalam kegiatan tersebut untuk diarsip secara personal.

Proses pengajuan surat keputusan dengan tahapan yang terjadi pada sistem eksisting membutuhkan waktu yang khusus. Proses pengarsipan manual yang dilakukanpun membuat arsip rentan hilang dan rusak serta perolehan informasi terkait histori SK menjadi sulit, karena histori kegiatan tidak tercatat dengan baik. Tentu saja hal ini dapat menyebabkan proses pengambilan keputusan terkait SK kegiatan seringkali menjadi tidak tepat.

Kelemahan sistem eksisting ini diatasi dengan melakukan reenginering proses bisnis pengarsipan SK. Model pengarsipan baru yang dirancang adalah Record Center pengarsipan SK digital yang dapat disharing sehingga menjadi sumber informasi bersama. Semua SK yang diproduksi dan disimpan dalam media yang sama secara digital. Pengelolaan yang tidak lagi berbasis kertas dan model pengarsipan terpusat dapat memudahkan otomatisasi distribusi file arsip ke seluruh civitas yang berhak atas SK terkait.
Perubahan proses dilakukan dengan melakukan pengajuan SK melalui sistem terkomputerisasi berbasis web. Pengajuan SK melalui sistem ini dilakukan koordinator kegiatan dengan mengirimkan draft SK yang siap diberi nomer SK dan menentukan anggota yang berhak atas arsip SK. Selanjutnya SK dicetak unit Humas untuk dimintakan tanda tangan direktur sebagai pimpinan utama. SK yang telah selesai diupload kembali ke sistem oleh Humas untuk disimpan sebagai arsip bersama.

\subsection{System and Software design}

Sistem Record Center yang dibutuhkan oleh universitas dalam pengelolaan surat keputusan, diakses oleh 3 jenis user. Ketiga jenis user yaitu koordinator kegiatan pengusul SK, Humas dan Anggota. Koordinator pengusul mengajukan draft SK melalui sistem. Draft SK tersebut dikelola oleh unit humas sampai selesai ditandatangani pimpinan utama. Setelah selesai maka SK yang sudah jadi diupload dan simpan di sistem sebagai arsip. Arsip dapat dicari oleh anggota yang terkait dengan SK yang disimpan. Sistem record center yang dibuat didesain dengan arsitektur umum seperti gambar 2 berikut:

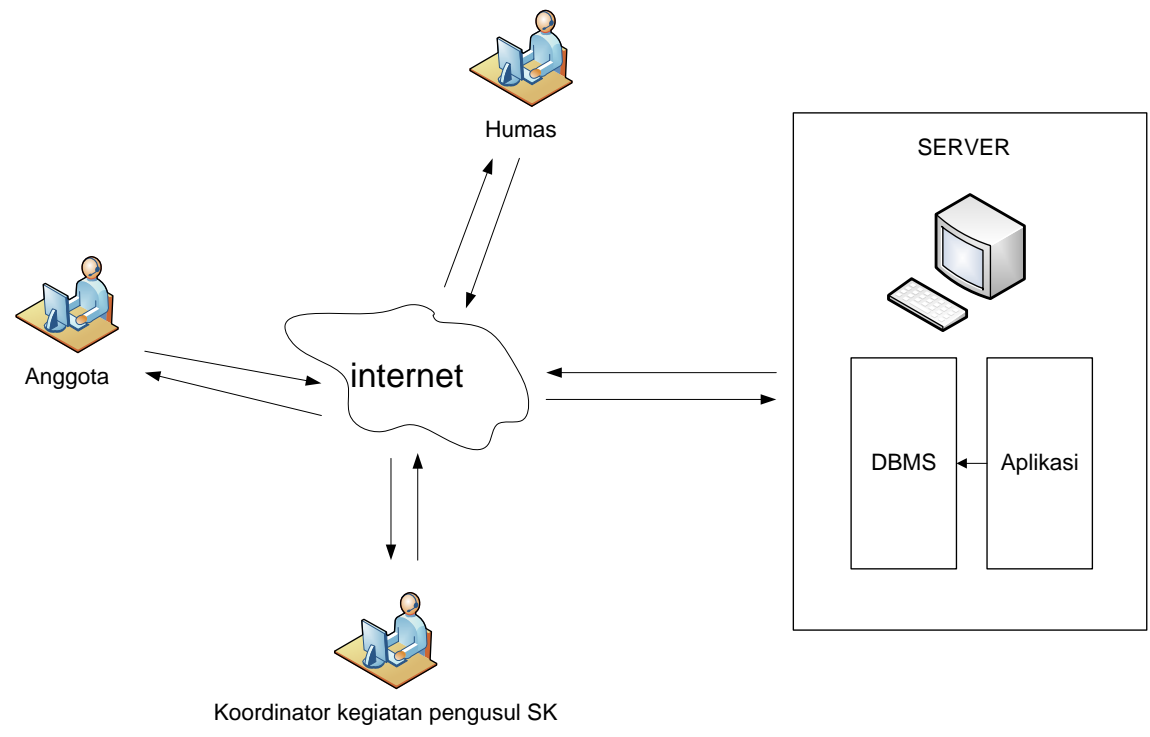

Gambar 2. Arsitektur Sistem

Sumber: Hasil desain, 2018

Sistem ini diimplementasikan menggunakan bahasa pemrograman PHP, Web Server Apache dan MySQL. Software ini dipilih karena 3 Software ini bersifat open source sehingga lebih mudah dalam pengembangannya.
Hubungan semua entitas objek yang terlibat dalam sistem digambarkan relasinya dalam Entity Relationship Diagram pada gambar 3 sebagai berikut ini: 


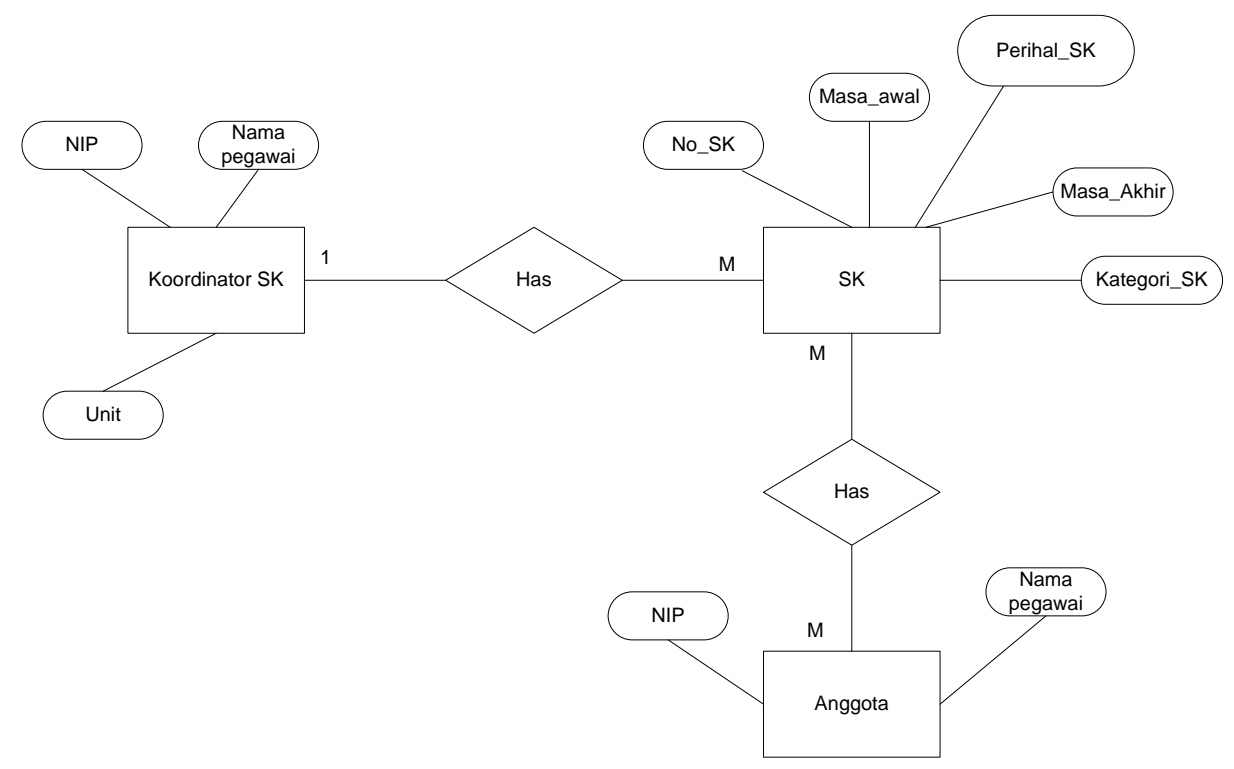

Gambar 3. Entity Relationship Diagram

Sumber: Hasil desain, 2018

Hasil design hubungan relasi entitas pada gambar diatas menggambarkan hubungan aliran dokumen terjadi antara koordinator SK, dokumen SK dan anggota yang terlibat dalam SK. Seorang koordinator SK dapat mengajukan surat keputusan beberapa kali ke dalam sistem. Dokumen SK yang diajukan melalui sistem hanya dapat dikoordinatori oleh seorang koordinator. Dokumen SK dapat berelasi dengan obyek anggota dimana relasi yang terjadi yaitu sebuah dokumen SK dapat dimiliki oleh banyak anggota dan 1 anggota dapat memiliki banyak arsip surat keputusan.
Hubungan relasi yang terjadi antar entitas pada ERD diatas menjadi dasar penentuan struktur database sistem Record Center File SK. Mapping dan normalisasi dilakukan agar database yang disiapkan tidak mengalami anomali dan redudansi data, sehingga struktur database dapat mengelola data dengan efektif dan menyimpan data dalam ruang memori secara efisien. Relasi antar entitas menghasilkan 11 tabel ternormalisasi. Tabel yang telah ternormalisasi tersebut terhubung satu dengan yang lainnya seperti relasi yang tampak pada gambar 4 berikut ini:

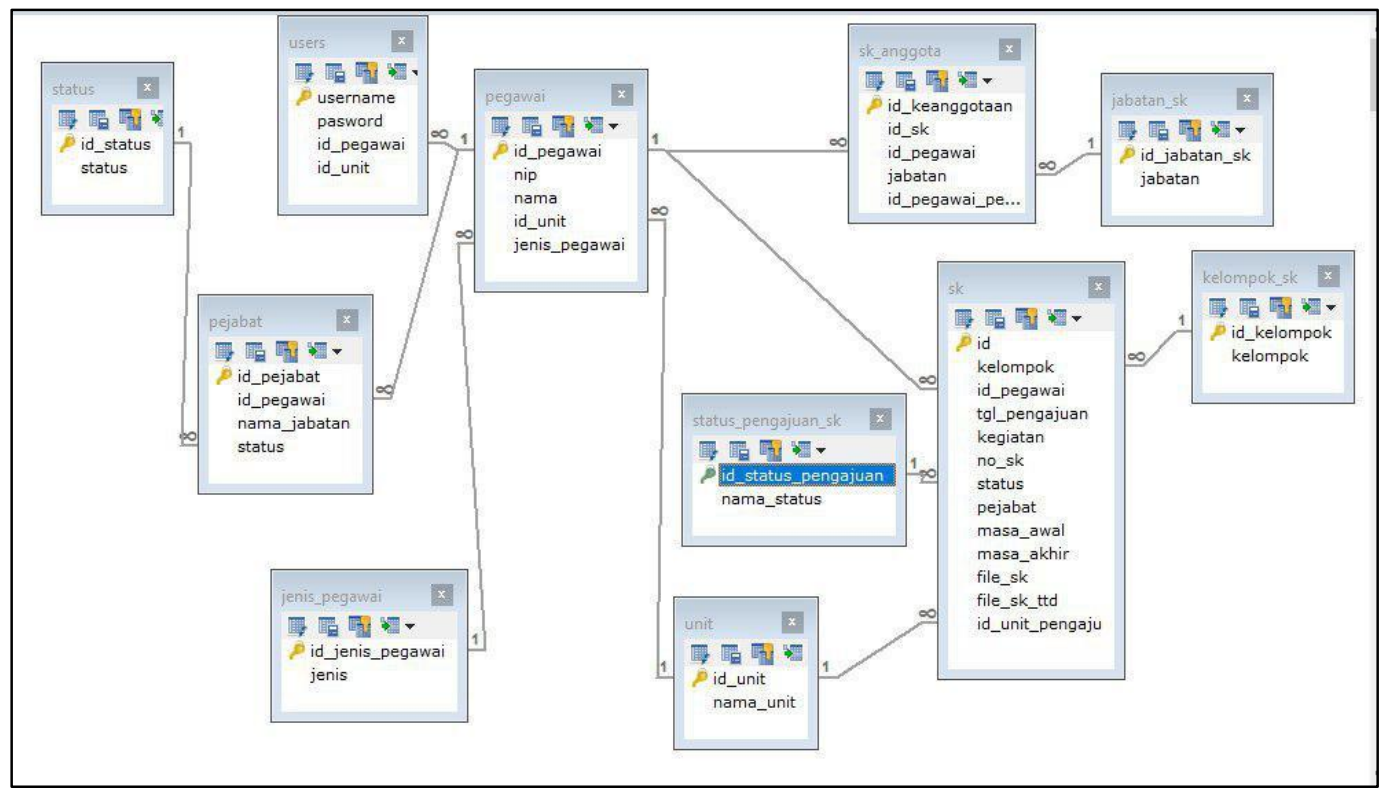

Gambar 4: Relasi Tabel

Sumber: Hasil perancangan, 2018 
Perubahan proses eksisting nantinya akan dimplementasi ke sistem baru dengan aliran hubungan seperti yang tergambar dalam diagram konteks pada gambar 5 berikut ini:

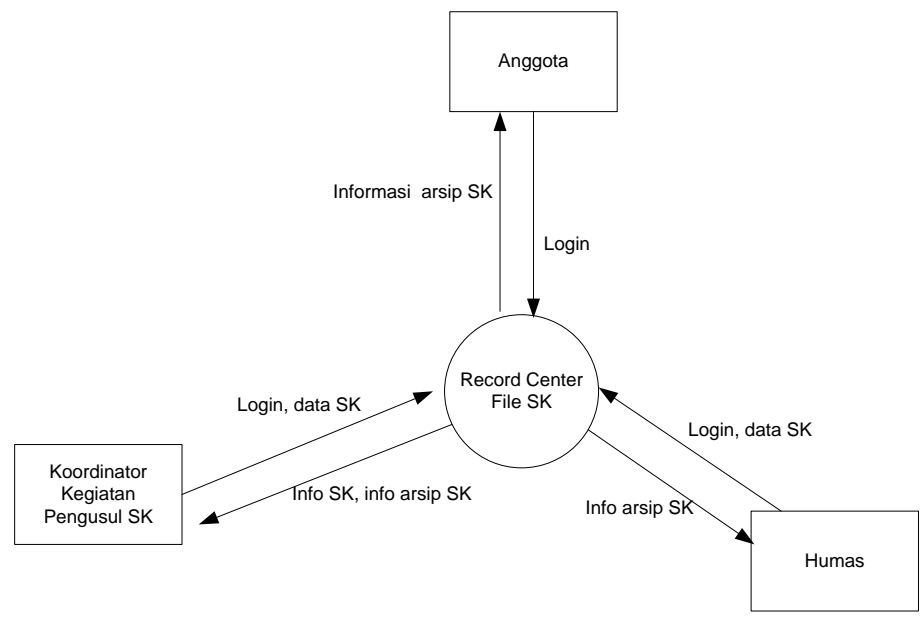

Gambar 5. Diagram konteks

Sumber: Hasil desain, 2018

Sistem Record Center dapat diakses dengan user priveledge berbeda bagi setiap user. Koordinator kegiatan pengusul SK memberikan data terkait SK berupa detil data pengusul dan melakukan upload file SK yang ingin ditandatangani. Koordinator kegiatan pengusul SK juga berkewajiban untuk menentukan struktur anggota penerima SK. Bagian Humas bertanggungjawab mendownload draft file SK kemudian menguploadkan kembali file SK yang sudah selesai agar dapat diakses oleh semua anggota yang tercantum dalam struktur sebuah SK yang berhak atas SK terkait dengannya. Detail desain proses digambarkan seperti gambar 6 berikut

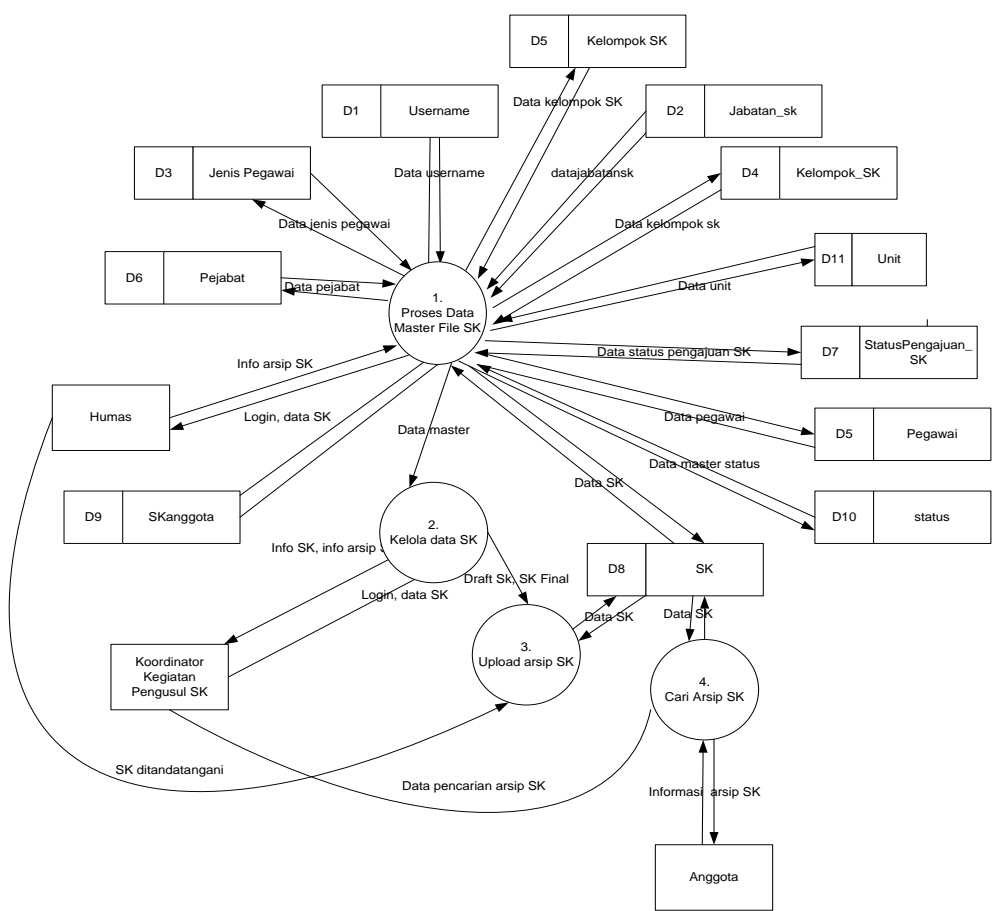

Gambar 6. Diagram Arus Data

Sumber: Hasil perancangan, 2018 


\subsection{Implementation and unit testing}

Alur bisnis sistem yang dirancang pada tahapan sebelumnya. Sistem Record Center diimplementasikan menggunakan bahasa pemrograman PHP, Web server Apache dan MySQL. Ketiga software ini bersifat open source sehingga mudah dalam pengembangannya.

Sistem record center arsip yang terdiri dari 4 proses utama diimplementasikan dalam 15 form yang terintegrasi dengan 11 tabel yang telah didesain. Implementasi setiap subproses berjalan dengan baik. Hal ini tampak saat setiap sub menu pada aplikasi sistem arsip diujikan tidak terjadi error program dan telah memenuhi spesifikasi yang telah didesainkan.

\subsection{Integration dan system testing}

Pada tahapan ini sistem aplikasi yang dihasilkan diujikan secara utuh sebagai keseluruhan proses pengarsipan surat keputusan universitas secara digital. teknik pendekatan pengujian yang dilakukan menggunkana teknik black-box. Pendekatan ini ditujukan untuk memastikan semua fungsi yang disediakan dalam sistem berjalan sesuai fungsi yang didefinisikan pada fase analisa dan desain sistem, Pengujian terhadap fungsional sistem pengarsipan SK menghasilkan factor correctness, reliability, efisiency, integrity dan usability dari product yang dihasilkan secara keseluruhan dalam penelitian ini berhasil baik. Hal ini diperoleh dari strategi debugging yang dilakukan pada sistem pengarsipan SK, dimana sistem bekerja tanpa error.

Pengarsipan SK dimulai user dengan melakukan login sesuai dengan hak aksesnya. Login yang berhasil akan menampilkan menu utama seperti gambar 7 berikut ini:

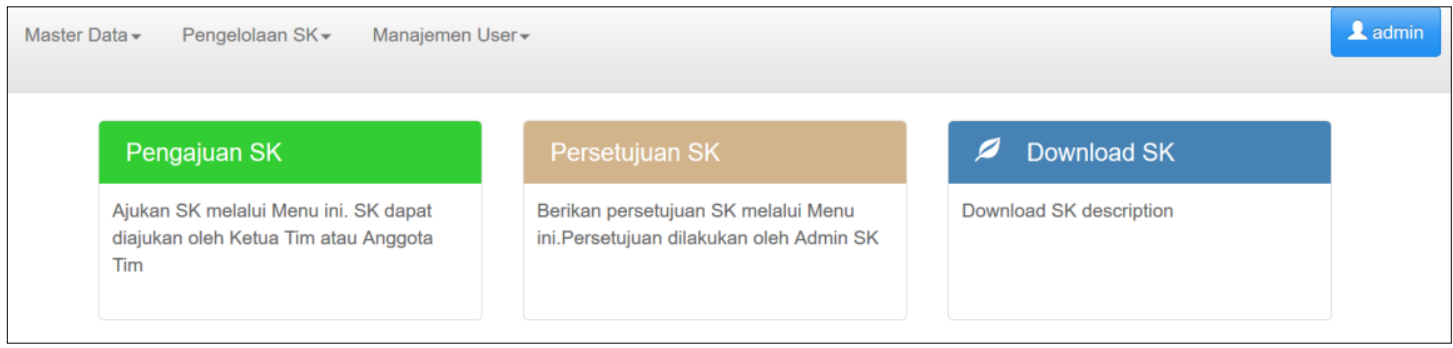

Gambar 7. Form utama

Sumber: Hasil pengujian, 2018

Proses pada sistem arsip ini dimulai oleh unit Humas. Humas memulai dengan menginputkan data master terlebih dahulu dengan mengakses menu Master data. Setiap form master data akan memiliki fasilitas untuk menambahkan data baru, mengedit dan menghapus data yang sudah ditambahkan ke database dan melakukan pencarian ke data master yang formnya sedang aktif.

Setelah data master terinput, maka proses pengelolaan SK baru dapat dilakukan. User sebagai koordinator kegiatan pengajuan SK, melakukan input data melalui form seperti dibawah ini setelah memilih menu pengajuan SK. 


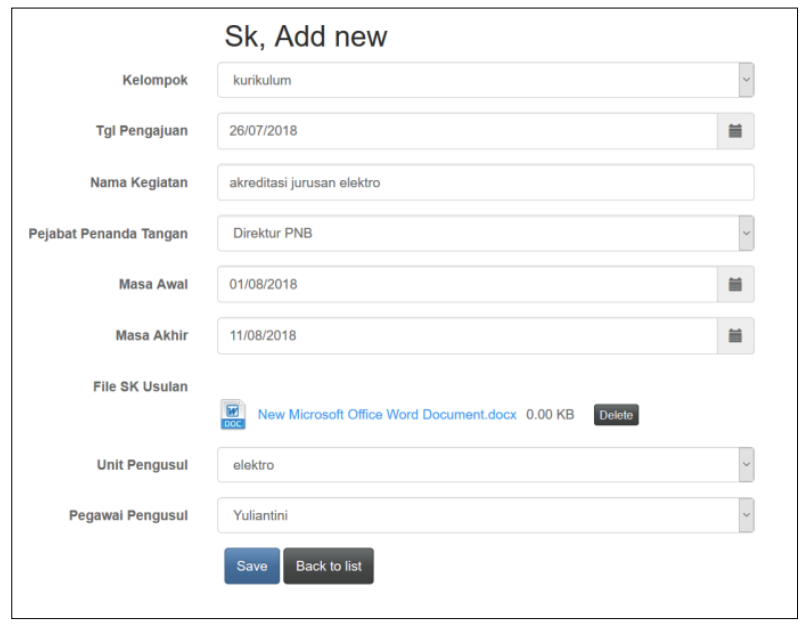

Gambar 8. Form master SK

Sumber: Hasil pengujian, 2018

Data yang diinput disimpan ke database dan kemudian menunggu pengurusan tanda tangan oleh unit Humas. Data SK yang telah ditandatangani diubah dan diarsip oleh humas melalui menu persetujuan SK dan arsip SK siap didistribusikan.
Anggota yang berkepentingan pada arsip SK dapat melakukan pencarian pada menu download SK. SK yang siap didownload ditampilkan seperti gambar 9 berikut ini

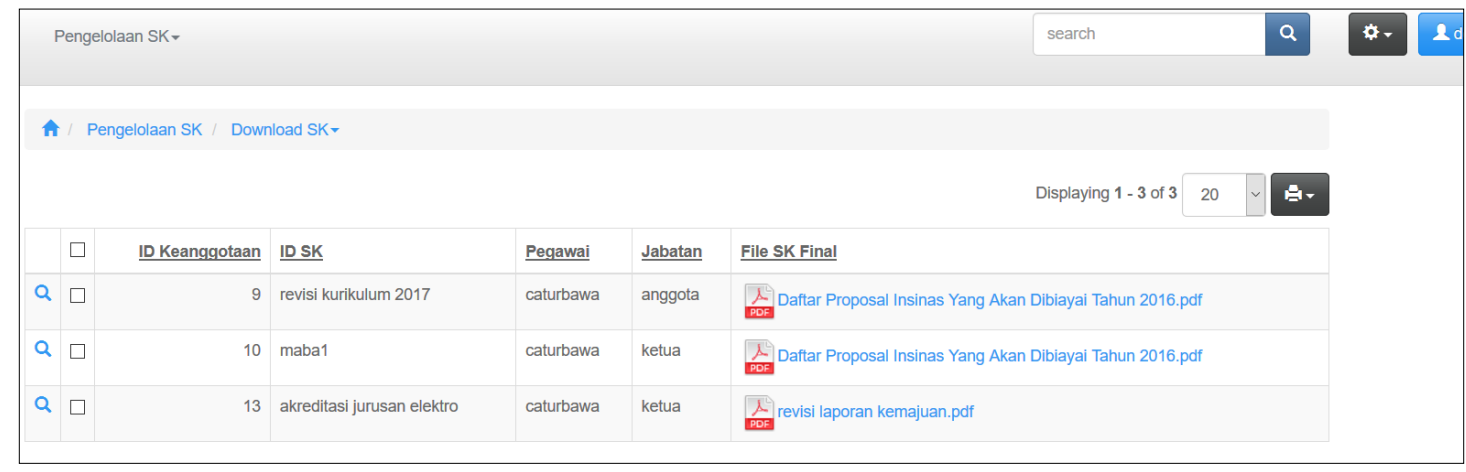

Gambar 9. Form download sistem

Sumber : Hasil pengujian, 2018

\section{SIMPULAN}

Simpulan yang dapat diambil berdasarkan hasil penelitian ini adalah sebagai berikut:

1. Record Center File SK dapat digunakan sebagai media arsip bersama sekaligus personal sehingga pengarsipan SK tidak secara personal dan manual.

2. Implementasi sistem, pengelolaan arsip SK secara digital membuat proses pengarsipan SK menjadi lebih efisien dan efektif. Hal ini dikarenakan semua proses dilakukan berbasis elektronik sehingga tidak menggunakan resource yang besar baik dari sumber daya manusia, media penyimpan dan waktu distribusi.

\section{DAFTAR PUSTAKA}

[1] Angry Ronald, Violitta Yesmaya, Muhammad Danaparamita ,Personal Security Tracking based on Android and Web Application, Telkomnika Vol 16, No 2 
[2] Arsip Nasional Republik Indonesia, Peraturan Kepala Arsip Nasional Republik Indonesia Nomor 14 Tahun 2012 Tentang Pedoman Penyusunan Kebijakan Umum Pengelolaan Arsip Elektronik

[3] Cenk Toremis; Enis Karaarslan, A web technology based smart emergency room system recommendation: SmartER, Computer Science and Engineering (UBMK), 2017, International Conference on IEEE

[4] Chandraprabhat Sahu, Ayonija Pathre, A cloud data access control and lockbox approach for data sharing, Information, Communication, Instrumentation and Control (ICICIC), 2017 International Conference on, IEEE

[5] Dessy Irmawati, Yuniar Indrihapsari ,Sistem Informasi Kearsipan Untuk Meningkatkan Kualitas Pelayanan, Jurnal Pendidikan Teknologi dan Kejuruan, Volume 22, Nomor 2, Oktober 2014

[6] Gudakesa,R, M.Sukarsa, dan GM.A Sasmita, Two-Ways Database Synchronization In Homogeneous DBMS Using Audit Log Approach, Journal Of Theoretical and Applied Information Technology vol. 65 no.3 , 2014

[7] Jian Shen ,Tianqi Zhou, Xiaofeng Chen, Jin Li , Willy Susilo, Anonymous and Traceable Group Data Sharing in Cloud Computing, IEEE Transactions on Information Forensics and Security, Volume: 13, Issue: 4, April 2018

[8] Sularso Mulyono, Drs, dkk, Manajemen Kearsipan. Cetakan: I, 2011 Penerbit: UNNES Press Semarang ISBN: 978-602-8467-5
[9] Triono Dul Hakim, Pengelolaan Arsip di Era Teknologi Informasi, Jurnal Ilmu Budaya Vol 11 no 22, Februari 2015

[10] Machsun Rifauddin , Pengelolaan Arsip Elektronik Berbasis Teknologi, Khizanah AlHikmah Jurnal Ilmu Perpustakaan, Informasi, dan Kearsipan, 4(2),168-178, (2016)

[11] Neal Fitzgerald, Using data archiving tools to preserve archival records in business systems, Glamatek Brisbane, Queensland, Australia neal.fitzgerald@gmail.com access februari 2018

[12] Ratna Gangga Dewi , Oka Sudana , Made Sukarsa ," Implementasi Diagram Tree pada Rancang Bangun Sistem Informasi Bebayuhan Oton Berbasis Web “, Lontar komputer vol 83 desember 2017, Dec 5, 2017

[13] Sommerville, I. (2011) Software Engineering 9th Edition. Addison-Wesley.

[14] Sun Min, Design and Implementation of A Monitoring System for Geological Archives, Telkomnika, Vol. 13, No. 4, December 2015

[15] Thomas M. Kroeger, Joel C. Frank, Ethan L. Miller, The case for distributed data archival using secret splitting with Percival, Resilient Control Systems (ISRCS), 2013 6th International Symposium on IEEE , 10.1109/ISRCS.2013.6623777

[16] Widiatmoko Adi Putranto, Pengelolaan Arsip Di Era Digital, Diplomatika, Vol. 1, No. 1 September 2017

[17] Wisswani NW IGNB Catur Bawa, WebBased Honorarium Confirmation System Prototype, Journal of Physics: Conference Series, IOP Publishing, 2018 